\title{
The Physical Principles Elucidate Numerous Atmospheric Behaviors and Human-Induced Climatic Consequences
}

\author{
Ernani Sartori \\ Universidade Federal da Paraíba, João Pessoa, Brazil \\ Email: e.solar@hotmail.com
}

Received September 20, 2012; revised October 22, 2012; accepted November 12, 2012

\begin{abstract}
The principles that govern the operation of an open and a closed evaporator are relevant for the understanding of the open and "closed" Earth's atmospheric behaviors, and are thus described. In these greenhouses, the water is included, otherwise the heat and mass balances do not match. It is incorrect to consider the radiation as the only energy transfer factor for an atmospheric warming. Demonstrations show that when the greenhouse effect and the cloud cover increase, the evaporation and the wind naturally decrease. Researchers did not understand why reductions in surface solar radiation and pan evaporation have been simultaneous with increased air temperature, cloudiness and precipitation for the last decades. It is an error to state that the evaporation increases based solely on the water and/or air temperatures increase. Also, researchers did not comprehend why in the last 50 years the clouds and the precipitation increased while the evaporation decreased and they named such understanding as the "evaporation paradox", while others "found" "the cause" violating the laws of thermodynamics, but more precipitation is naturally conciliatory with less evaporation. The same principle that increases the formation of clouds may cause less rainfall. Several measurements confirm the working principles of greenhouses described in this paper. The hydrological cycle is analyzed and it was also put in form of equation, which analyses have never been done before. The human influence alters the velocity of the natural cycles as well as the atmospheric heat and mass balances, and the evaporation has not been the only source for the cloud formation. It is demonstrated that the Earth's greenhouse effect has increased in some places and this proof is not based only on temperatures.
\end{abstract}

Keywords: Evaporation; Clouds; Air Water Temperature; Paradox; Hydrological Cycle; Precipitation; Rain; Drought; Global Warming; Radiation; Convection; Aerosols; Greenhouse Effect; Wind; Particulates; Atmosphere; Climate; Human-Induced

\section{Introduction}

In general, the attempts to describe climatic changes have been made solely using extensive experimental data in order to find empirical connections among phenomena. However, due to the extremely variable, complex, random and vast nature of the atmospheric processes with their isolate data, almost an infinite time is needed to get an approximate conclusion on a single phenomenon, and a definition may not be found or not found with confidence, too.

However, parallel to the experimental data we have the fundamental laws of physical principles that lead us on a straight line over these tremendous variability and complexity that do not "speak" clearly. Theoretical principles and experimental data should be used jointly.

The general literature usually makes representations of the Earth's greenhouse effect through the common rural greenhouse. However, this is an incomplete representation because it does not include water, which corresponds to much more than $70 \%$ of the planet's surface because most part of the remaining 30\% is covered by vegetation, which also contains much water that evaporates and thus adds heat and mass to the atmosphere. The water makes all the difference since such a large amount changes all the heat and mass balances of the atmosphere.

It has been reported that in the last 50 years in some places of the world (e.g., Russia, India, USA, and Venezuela), the clouds and the rain increased while the pan evaporation decreased in these same places and periods. Using the information from the conventional hydrological cycle, some researchers asked how less evaporation could form more precipitation and then named such understanding as the "evaporation paradox" (e.g., [1]), who also concluded that more precipitation is not conciliatory with less evaporation. However, when we pay close attention to the fundamental laws and first principles that govern the evaporation and the greenhouse effect as well as knowing that the nature doesn't work through para- 
doxes, we see that the evaporation decreases in such conditions and we can explain all these issues naturally and correctly, and which solution is consistent and has physical meaning, in contrast to previous solutions based only on empirical hypotheses. Therefore, more precipitation is perfectly and naturally conciliatory with less evaporation. The evaporation is in the core of the greenhouse effect and accurate understandings and directions are thus enormously required.

Also, various researchers (e.g., [2,3]) did not understand why reductions in surface solar radiation and pan evaporation have been simultaneous with observed increase in air temperature, cloudiness and precipitation in various parts of the world for the last decades. RoderickFarquhar [3] draw the corresponding conclusion and "found" "the cause" through an incorrect understanding that violates the laws of thermodynamics and thus of the nature, i.e., creating more energy from less energy. The main reasons for the increase of the cloudiness, precipitation, humidity and temperatures while the pan evaporation, the surface radiation and the winds have decreased are given, which explanations correct invalid understandings.

It has been a general belief that the evaporation must increase in an increasing greenhouse effect. Such belief often comes from considering the water temperature as having almost the sole and total power for influencing the evaporation. Although evaporation is a strong function of the water temperature, this is not the only parameter that affects the evaporation and it cannot be used isolately for this purpose. Other parameters such as the air temperature, relative humidity, wind velocity and even the atmospheric pressure have relevant influences as well as some heat transfer factors and the greenhouse effect have. When a water surface is exposed to the atmospheric air, all these variables affect the evaporation simultaneously, some having more influence, some less, some increasing and some decreasing the evaporation, and thus they should be analyzed together and carefully. Another example is in relation to the air temperature influence, which increase plays a very important role in the evaporation decrease. In this context, it is also a general procedure to take into account the radiation as the only heat transfer factor influencing an atmospheric warming, but this is incorrect. Besides the fact that the heat and mass balances do not match if only one factor is considered, the convection alone represents the change of all the wind condition inside the greenhouse and this is of paramount relevance for its warming effects and climatic changes.

Satellite data [4] showing that the wind speeds are decreasing globally associated with the cloud cover and aerosols increase is a proof and another confirmation, among the several ones presented, of the physical princi- ples demonstrated in this paper and also reveal that the Earth's greenhouse is changing from an open to a more "closed" condition, and thus from the forced to the free convection, i.e., decreasing winds, as previously expected by this author. These results are also corroborated by [5] who compiled decades-long database of aerosols measurements and found that clear sky visibility has decreased over land globally from 1973 to 2007, indicative of an increase of particulates and darkness in the air over the world's continents during that time. Pryor et al. [6] also did not understand why winds have decreased, but a study by them based on measurements showing that the average and peak winds have decreased $10 \%$ or more per decade from 1973 to 2005, especially in the Midwest and the East of the USA, is another confirmation of the demonstrations of this paper on the correct working principles of greenhouses as well as that the Earth's greenhouse effect has increased in some places of the world, with the consequent reductions in evaporation, surface radiation and winds, while the clouds, the precipitation, the humidity and the water and air temperatures have increased. The work [7] completes and confirms the demonstrations of this paper on the correct working principles of greenhouses as well as on the real behavior of the Earth's greenhouse effect through those authors' findings which show that more than 170 large lakes water temperatures worldwide increased since 1985.

All of the issues above and several other relevant ones are elucidated and solved correctly. The hydrological cycle is also analyzed physically and mathematically, which analyses have never been done before.

\section{The Thermal Behaviors of an Open and of a "Closed" Atmosphere}

\subsection{The Thermal Behaviors of Equivalent Systems Built on Earth}

To better understand how an open and a “closed” Earth's atmosphere behave thermally, it is important and didactic to make a brief description of the thermal behaviors of equivalent systems built on Earth, which principles are valid for both systems. Sartori [8] analyzed this subject in depth and helps for the present understanding.

The open evaporator suffers direct influence from the wind flowing over its water surface and then works under the forced convection, while the closed evaporator (solar still) has a transparent cover and thus no wind exists inside the system. Also, the greenhouse effect and the free convection take place below the cover. The forced convection over the open evaporator is converted into the free or natural convection (works according to temperature and density gradients) inside the closed system. This makes a big difference in terms of warming and water balance of both systems. 
The thermal operations of the open (free water surface) and of the closed evaporator (greenhouse effect) are essentially the same. After the water layers of both systems are heated by the solar radiation, they lose heat by radiation, convection, conduction and heat and mass by evaporation, and thus heat the corresponding environments. Thus, there are more forcings for the ambient warming than only the radiative one. If the heat transfer processes by evaporation, convection and conduction are not taken into account, the energy balance does not match. The heat released per square meter only by evaporation corresponds to about $60 \%$ of the total heat transfer released, which obviously cannot be neglected, and is also much greater than the corresponding radiation transfer from the surface to the cover or to the atmosphere $[8,9]$. Moreover, besides the latent heat addition, the evaporation adds water mass to the greenhouse and thus alters the mass balance, which on its turn alters the heat balance of the system. The water temperature is the final result of all heat gains and losses of the water layer and also depends on the physical characteristics of the system.

The general literature on global warming uses to make the representation of the Earth's greenhouse effect through the common rural greenhouse. However, this is an incomplete representation because it does not include water, which corresponds to much more than $70 \%$ of this planet's surface because a great part of the remaining 30\% is covered by vegetation, which also contains much water that evaporates. The water makes all the difference since such a large amount changes all the heat and mass balances of the planet and thus only deserts and constructions could be neglected from this process. We could say that this is a planet of evaporation.

The evaporated water in the closed evaporator in contact with the glass cover condenses (whenever the inside air dew point temperature is higher than the cover temperature) and runs down, being the condensate, pure water, collected at the cover end. The more the water vapor within the closed evaporator, the more the condensed (precipitable) water, but the higher the saturation condition, the higher the air pressure, and slower becomes the evaporation.

Figures 3-5 from E. Sartori [8] bring lots of important information on the temperatures and evaporation rates of both systems, which were compared theoretically and experimentally under the same physical and environmental conditions, and in this way close agreement was obtained. The temperatures of the closed system are much higher than the ones of the open evaporator, but despite this the evaporation from the open evaporator is much higher than that of the closed one. The effect of the wind over the open evaporator dissipates the heats and mass much more and more rapidly than this happens in the closed evaporator, and thus does not allow the corresponding water layer to reach higher temperatures. Over the open evaporator there is also a much lower humidity than that within the closed evaporator and this allows a greater withdrawal of water vapor, thus causing higher heat and mass transfer by evaporation. The greenhouse effect of the closed system also plays a very important role to make its inner temperatures to attain much higher values. Moreover, inside the closed evaporator, saturation is reached which does not allow faster evaporation. Within an igloo, the outside temperatures of about $-50^{\circ} \mathrm{C}$ are transformed to about $+16^{\circ} \mathrm{C}$ due to the cover that converts the outdoor forced convection (high heat loss by bodies) into the free convection inside and also due to the addition of sensible heat (radiation, convection) and latent heat (evaporation from sweat) to the inner air by human bodies.

In Figure 5 from E. Sartori [8], we can also see a time lag of about $2 \mathrm{~h}$ between the evaporation of the open and closed evaporators. This is due to the higher thermal inertia of the closed system (cover influence) and to its higher water vapor concentration that delay and reduce the evaporation. Therefore, we can see that the water temperature is not the only responsible for a higher and quicker evaporation and cannot be considered alone for such evaluation.

It is also very important to note that the water of the closed evaporator receives less energy than the water of the open evaporator due to the influence of the glass cover. For typical values of the glass cover solar reflectance $\rho=0.08$ and its solar absorptance $\alpha=0.05$, the transmitted solar energy becomes $\tau=0.87$, and then the solar radiation that reached the water of the closed system was $13 \%$ lower, but even so the corresponding temperatures were higher than those of the open evaporator. This is because the multiple emissions and reflections by the cover increase the amount of energy trapped inside the greenhouse as well as the free convection due to the cover substantially reduces the heat loss from the water. This is how greenhouses behave and it is another demonstration on why any considered amount of solar energy and water temperatures are not sufficient to guarantee higher or lower evaporation and cooling when the greenhouse effect is involved.

The air temperature increase also plays a very important role in the evaporation decrease. It is well known that the evaporation is directly proportional to the partial pressures difference $\left(\mathrm{P}_{\mathrm{w}}-\mathrm{P}_{\mathrm{a}}\right)$ between the water and air. Since the pressure is function only of temperature, that is, on $t_{w}$ and $t_{a}$, respectively, then when $t_{a}$ increases, $P_{a}$ also increases and the difference $\mathrm{E} \sim\left(\mathrm{P}_{\mathrm{w}}-\mathrm{P}_{\mathrm{a}}\right)$, or the evaporation, decreases. We should also know what this means physically. A higher ambient temperature means a higher air pressure that puts a higher resistance or difficulty for 
the air to absorb more water vapor. In the same way as the voltage difference is the driving force for the electrical current to flow, the temperature difference is the driving force for the heat to flow and the pressure difference is the driving force for the mass to flow, and so, the lower this difference (with higher $t_{a}$ or lower $t_{w}$ ), the lower is the flow of heat by convection and conduction, and lower is the heat and mass by evaporation. Additionally, the specific heat of the air is only $24 \%$ of that of the water and this means that the air temperature fluctuates more quickly than the water temperatures and also that the air attains higher temperatures than those of the water of big reservoirs, thus causing quicker variations in $\mathrm{P}_{\mathrm{a}}$. Also, the thermal inertia of big water reservoirs is high and then the corresponding temperatures vary slower and lower, causing the relative increase of the air temperature to produce lower evaporations.

Additionally, it is very important to mention that the atmosphere inside the closed evaporator is exactly the same as the one of the open system, with the same atmospheric constituents, and nothing of the normal Earth's atmosphere components has been modified due to the addition of a cover. Only the water vapor may increase until the saturation in a closed system. Comparing Figures 3 and 4 from E. Sartori [8] we can verify that the closed system (greenhouse effect) has the capacity to increase its temperatures more than $30^{\circ} \mathrm{C}-40^{\circ} \mathrm{C}$ above the ambient one and more than $20^{\circ} \mathrm{C}-30^{\circ} \mathrm{C}$ above the open evaporator temperature, and this happens with the normal atmospheric components without any addition of $\mathrm{CO}_{2}$. Furthermore, it is generally said that the higher the ambient temperature, the higher the water vapor the atmosphere can hold and thus more water vapor can absorb more gas, but within any greenhouse more water vapor can hold only the previous fixed mass amount of gas, which did not change and even so the temperatures increased substantially.

If in place of a transparent cover we had an opaque one, the radiant energy would be mostly absorbed by this cover and then the transmitted energy would be zero, and then the energy reaching the greenhouse would be substantially reduced. The absorbed energy is converted into heat and afterwards part of it is emitted back to the outside and part to the inside. Since the wind inside does not exist, the inner ambient continues airless and with high humidity as well as a warming and the process of evaporation-condensation are kept, although much less than with a transparent cover. The difference in warming would be similar to the changing of a glass roof of a house (without ceiling) by an opaque roof (without ceiling), both under a torrid sun. Although reduced, the ambient inside the second condition continues warm.

It is also important to mention other features of open and closed systems where there is evaporation. When it is said that the atmosphere has the capacity to absorb more moisture with higher temperatures, this means that higher temperatures can hold more moisture only if sufficient mass of water vapor exists or is added to the atmosphere (as happens in the closed evaporator), which does not happen in deserts, that is, the temperature itself does not create humidity. Such capacity of the air exists, but it happens only when needed and this must not be confused with the evaporation capacity.

Any free water surface and its surroundings exposed at the same time to the atmosphere are both submitted to the same environmental conditions, that is, the solar radiation, the wind, the relative humidity, the ambient temperature and even the atmospheric pressure play direct influences on the water layer and on its surroundings in the same way. Like for the other environmental parameters, the relative humidity, for example, is the same for both systems and affects them in the same way. Only the relative humidity (which is also the final result after all heat and mass interactions with the atmosphere) that exists over the water surface affects the corresponding evaporation, not a distant one, and the evaporation from the surroundings does not affect directly the evaporation from a pan and vice-versa. A piece of clothing outdoors dries according to the environmental conditions, not according to the evaporation from distant places.

\subsection{The Thermal Behaviors of the Open and “Closed" Earth's Atmospheres}

\subsubsection{The Open (Cloudless) Atmosphere-Forced Convection}

The thermal behavior of the open Earth's atmosphere is essentially the same of the open evaporator, since the Earth's surface works as an open evaporator and all the incoming and outgoing heat and mass transfer processes are the same in both systems. When a free water surface is exposed to the atmosphere it suffers direct influence from all of the environmental parameters. The description is given below.

The incoming solar radiation that reaches the Earth's surface suffers reflection at the water surface and absorption in the water layer. Thereafter, the water exchanges heat with the atmosphere through simultaneous heat transfer processes by radiation, forced convection (predominantly) and heat and mass transfer by evaporation. Heat may also be lost by conduction from the water layer to the soil through the water reservoir base and sides. The solar energy, the wind, the relative humidity, the ambient temperature and even the atmospheric pressure play direct influences on the water layer. The convection is forced due to the presence of wind (Figure 1). 


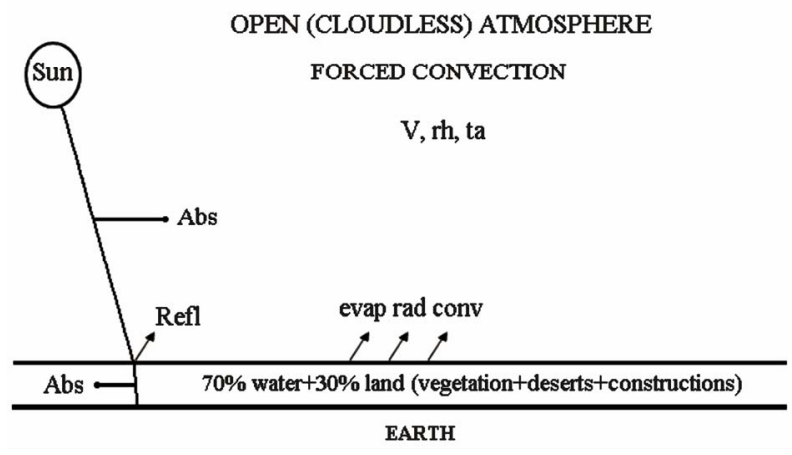

Figure 1. Schematic representation of the open (cloudless) atmosphere. Observe the high similarity of this behavior with that of the open evaporator of Figure 2 [8].

\subsubsection{The "Closed" (Totally Cloudy) Atmosphere- No Wind-Free Convection}

The greenhouse formed by the cloud cover (Figure 2) is very similar to a greenhouse where there is evaporation (Figure 2 from E. Sartori [8]). Thus, the thermal behavior of the "closed" Earth's atmosphere is also very similar to the one of the closed evaporator when the sky is totally or mostly covered by clouds, because this transparent cover (sometimes more "solid" and opaque) changes the conditions of radiation, convection and evaporation, and works in the same way as the glass cover, where there are multiple reflections and absorptions within both transparent media. It is important to note that for thermal radiation purposes and thermodynamic analysis it does not matter how many and what types of effects happen within the medium (clouds or glass), because what interests is only whether the cover is transparent or opaque, as well as for convection purposes does not matter whether the cover is transparent or opaque, because what interests is whether the atmosphere is "closed" or open. And in the same manner as the glass, clouds reflect, absorb and transmit thermal radiation. Also, such as the glass cover, the cloud cover converts the forced convection into free convection and causes a possible entire suppression of the wind. Covers keep heat and humidity below and humans live under the cloud cover.

The thermal operation of this "closed" system (greenhouse) is as follows. After reflection at the cloud upper surface and multiple reflections and absorptions within the cloud cover, the solar radiation that is transmitted through this transparent medium suffers absorption by the water vapor between the cloud cover and the surface, reflection at the Earth's water surface, absorption in the water layer and may also suffer reflection and absorption at the soil below the water layer when there is a shallow water layer. When there is a deep water layer, almost all of the solar radiation is absorbed in the few meters below the surface. Not all the reflected energy by the water and

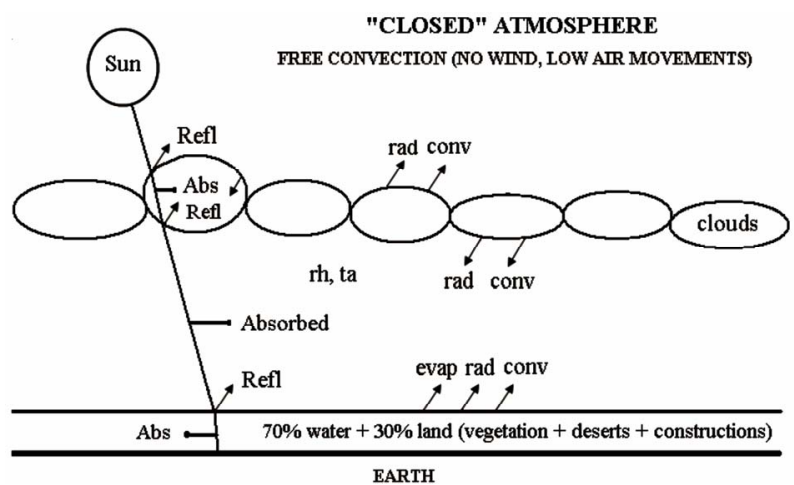

Figure 2. Schematic representation of the "closed" (totally cloudy) atmosphere.

basin surfaces is lost, because a portion is reflected back to the water by the cloud cover. A portion of the solar radiation absorbed by clouds is emitted back to the water, forming together with the reflected energy the greenhouse effect. The water exchanges heat with the ambient air through simultaneous heat transfer processes by radiation, free convection and heat and mass transfer by evaporation. The consequences of these processes are the heating of the water and of the ambient air within the greenhouse. Heat may also be lost by conduction from the water to the environment through the water layer base and sides. Heat from the water layer and from the water vapor inside the system reaching the cover plus a part of the solar energy absorbed by the cover (and thus converted into heat) are dissipated to the outer atmosphere by convection and radiation after conduction and convection through the cloud cover. The evaporated water in contact with cooler layers of the atmosphere condenses (whenever the air dew point temperature is higher than such layer air temperature) and forms water droplets and clouds, being this condensate and clouds transformed into rain. The more the water vapor in the "closed" atmosphere, the more the precipitable (condensed) water, but in the same way as it happens within the closed evaporator, the higher the saturation conditions, the higher is the air pressure $\left(\mathrm{P}_{\mathrm{a}}\right)$ inside the system and slower becomes the evaporation when saturation conditions approach. The free convection takes place due to the addition of a cover with the almost entire suppression of the wind and thus only very small air movements exist. When the cloud cover is complete or almost complete and transparent, the ambient below becomes airless and warm.

Such as other covers, the trend of a full cloud cover is to homogenize the air temperatures between the surface and an atmospheric layer inside such greenhouse and thus reducing the circulation of air currents. Temperature differences create pressure differences which create wind 
currents. Temperature differences are generated by the Sun, which heats up different parts of the planet in different ways. For the winds to exist or circulate, openings are necessary, like in our houses. Openings create pressure differences. A complete or mostly cloudy cover closes such openings and then converts the wind (forced convection) into still air or very small air movements (free convection) caused by density differences (very tiny temperature and pressure differences). If the sky is cloudy but there are wind jets, this means that the sky is not totally covered, because some parts of it are open and this generates greater temperature differences and thus greater air movements or winds.

The reflected solar energy by clouds has normally been considered as the only factor able to change the warming conditions below the cloud cover. To analyze the greenhouse effect only in terms of the radiation or of the reflected radiation is an incomplete analysis. If only one factor is considered, the energy balance does not match. Less energy has the potential to reduce the temperature, but as correctly explained in Section 2, there are many other factors that increase the warming within a greenhouse rather than where there is not this effect, and thus even with less energy received a greenhouse is able to increase the temperatures more than an open system can. Therefore, small reductions of the incoming solar energy are not sufficient to determine a supposed high cooling effect and generate other consequences. Even with some energy reduction, the greenhouse effect is built and its temperatures remain relatively high. When there is no wind for dissipating heats and humidity, all these heats (by radiation, convection and evaporation) remain inside this natural greenhouse. It is not only the reflected radiation by clouds that determine the heating conditions inside this greenhouse, being the heat added by evaporation and convection into the greenhouse much greater than that by the outgoing infrared radiation [8]. Therefore, if clouds fully cover the sky but the solar transmittance is high, then airless and warm conditions will exist inside the greenhouse independently of relatively small variations of the energy received from the Sun, because the winds decrease with any cover increase.

This also eliminates those kinds of proposals for spraying sea water particles into the atmosphere (e.g., [10]) aiming at increasing the amount of clouds in order to increase reflectivity. Because the reflectance is a property of surface and not of volume or thickness, and depending on the color, opacity and "solid" conditions of clouds, as well as knowing that the cloud cover works as a blanket, the radiation reflectivity may decrease and the warming increase. Additionally, the absorption is a property of length of the medium in the radiation direction, and then the cloud absorption of incoming and outgoing radiation increases, leading to a further greenhouse effect.
Such proposal also represents another absurd because in the nature everything that rises must come back, then if we put more salty water above, more rain will come back, more intensely, more irregularly and loaded with corrosive salt particles. Satellite data [11] showed that clouds over oceans produce more rain than the previous estimations. This emphasizes that the referred consequences may happen over land, too. And it is another type of uncontrollable human interference on the climate.

As seen in Section 2, even with less energy received the inner ambient temperatures of the closed evaporator increase much more than the open evaporator ones. Although the water temperatures of the experiment [8] are higher than the normal ambient ones, this serves as an insight on how greenhouses work and is another demonstration on how an increasing greenhouse effect is able to increase the inner temperatures almost independent of some variations of the solar energy received. Moreover, such average water temperature of $47^{\circ} \mathrm{C}$ is the same $47^{\circ} \mathrm{C}$ used for measuring the Earth's infrared radiation at noon over the Northern Africa [12]. These analyses emphasize once again the importance of other factors on the building of the greenhouse effect, and therefore, the radiation or the reflected radiation cannot be used alone for determining the warming or cooling effect of the greenhouse.

While clouds continue increasing in amount and thickness but keep transparency, they transmit radiation and augment the greenhouse effect almost independent of some variation of the energy reflected by them. In a second condition, a very thick, opaque cloud cover (due to heavy rainy clouds, for example) transmits less solar radiation due to multiple reflections, absorptions and scatterings of radiation within the cloud cover, which processes attenuate the radiation in a great part. Due to its high thermal inertia, the water vapor works as a buffer: in the first case, the water vapor absorbs most of the incoming and outgoing radiation, and thus increases and delays the inner warming; in the second case, since there is almost no direct solar energy entering the greenhouse, the absorption of such radiation by the water vapor is almost null, then the absorption is due to the existing infrared radiation and then the air does not warm too much and may remain relatively cool.

In all of these issues, what really matters is to be aware on the principles that govern the greenhouse effect and how humans can influence such natural system, independently of the higher or lower solar energy received due to seasons or to Sun activities, since these conditions represent only natural variations (not controlled by humans) of an open system, and the human influence on climate is not and should not be tied to the amount of solar energy received. It is obvious that higher solar radiation corresponds to a higher atmospheric warming, but this has nothing to do with human interference. More 
understandings on these subjects will be given in the following sections.

\section{Real Data Confirm the Physical Principles}

It has been reported that in the last 50 years in some places of the world (e.g., USSR, India, USA, and Venezuela), the clouds and the rain increased while the pan evaporation decreased in these same places and periods. Using the traditional information which says that the evaporation should be the only source for the formation of clouds and rain, some researchers asked how less evaporation could form more rain and then named such understanding as the "evaporation paradox" (e.g., [1]), who also concluded that more precipitation is not conciliatory with less evaporation. It is also a general belief that the evaporation must increase in times or places of increased greenhouse effect. However, when we pay close attention to the fundamental laws and first principles that govern the evaporation and the greenhouse effect as well as knowing that the nature doesn't work through paradoxes, we can explain all these issues naturally and correctly with solutions that have physical meanings and are consistent. As demonstrated in this paper, when the air temperature, the humidity and/or the greenhouse effect increase, the evaporation decreases. This author also did a mathematical demonstration based on first principles which confirms perfectly that when these factors increase, the evaporation decreases. Due to space limitations it is not shown in this paper.

If now we consider a scenario where the Earth's greenhouse effect increases (due to a cloud cover and/or water vapor and other gases increase), we should know that the inner temperature and the air humidity increase, too. These are properties of all greenhouses where there is evaporation (as demonstrated above), as happens with the Earth's greenhouse, too. It is also known that most of the world and the 20th Century became wetter, with increasing precipitation and warming (e.g., [13-15]), especially in the last decades. According to the IPCC, from 1950 to $\sim 2000$ the air temperature increased $0.75^{\circ} \mathrm{C}$ (from $13.75^{\circ} \mathrm{C}$ to $14.50^{\circ} \mathrm{C}$ ). The IPCC also says that in this same period the sea surface temperature increased $0.5^{\circ} \mathrm{C}$. As also shown in the referred mathematical demonstration, even with this water temperature increase the evaporation decreases, due to the strong influence of the air temperature, of the air humidity and of the greenhouse effect on evaporation. The main message withdrawn from these results is that it is a strong error to state that the evaporation must increase in an increasing greenhouse effect based solely on the water temperature, solar radiation or even on the air temperature, and not taking into account the first principles that govern these effects as well as other variables that strongly affect the evaporation in the opposite sense at the same time. Less evaporation with more rain leads to wetter ambient conditions, being these results also in close agreement with the observations that "increasingly wet conditions have been found over the Amazon Basin” [15].

The referred mathematical demonstration also confirms that the evaporation decreased in this period in places where the mentioned conditions applied, as expected by this author. As known from basic laws, the evaporation per square meter and unit of time increases with the wind velocity and water temperature increase, and decreases with the air temperature, humidity, and atmospheric pressure increase. Figure 10 from E. Sartori [8] correlates all these factors and the Sartori equation ${ }^{1}$ [8,9,16-21] contains all these properties, and any combinations among these variables can be obtained correctly with it (very accurate and more accurate than at least 30 others, including those from [22]—see Appendix):

$$
E=0.0041 V^{0.8} L^{-0.2}\left(\mathrm{P}_{\mathrm{w}}-\phi \mathrm{P}_{\mathrm{a}}\right) / P
$$

where $E=$ evaporation rate $\left(\mathrm{kg} / \mathrm{m}^{2} \mathrm{~s}\right) ; L=$ surface length of water in the wind direction (m), $P=$ atmospheric pressure (Pascal); $\mathrm{P}_{\mathrm{a}}, \mathrm{P}_{\mathrm{w}}=$ water vapor partial pressures at the air and water temperatures (Pascal); $V=$ wind velocity (m/s); $\phi=$ relative humidity (fraction).

More humid places show lower evaporation than dry ones in the same way as clothes dry slower during a wet day and as demonstrated in Section 2. More humid places obviously have more precipitation than dry ones. The higher the precipitation, the higher the humidity and consequently lower is the evaporation. Also, through [8] and the present paper we can see that the evaporation within a greenhouse (free convection) is much less than that from a free water surface (forced convection) both under the same physical and meteorological conditions. This can also be demonstrated mathematically. When we put a cover over a free water surface we suppress the wind but not the convection because this only changes from forced to free convection. As a consequence, we also make the evaporation to change from the advection mode to the diffusion mode where the evaporation and the convection depend only on temperature differences (slow processes) and not on the bulk or gross and stronger motion and processes due to the wind flowing over water surfaces. Hence, more precipitation is perfectly and naturally conciliatory with less evaporation. It is also elemental that in a humid place the evaporation is lower and slower than in a dry one. Groisman et al. [14] show clearly that almost the entire world became more humid in the last 40 years.

\footnotetext{
${ }^{1}$ Although not related to evaporation directly, the paper [23] is strongly recommended because in it the fundamental principles of the boundary layer theory, which govern the fluid flows over wet and dry flat surfaces, are clearly demonstrated.
} 
The above demonstrations are also in perfect agreement with well-known works which have shown that the pan evaporation, the surface radiation and the winds decreased while the precipitation, humidity and cloudiness increased in many countries of the world in the last decades (e.g., [2,4,6,13,14,24]). Since in the last 50 years the cloudiness, the precipitation, the humidity and the temperatures increased while the pan evaporation, surface radiation and the wind decreased, this is the perfect proof that the Earth's greenhouse effect for the corresponding regions and periods increased, actually. When the greenhouse effect increases in an atmosphere where there is evaporation, the inner temperatures and the humidity in- crease while the evaporation, the surface radiation and the wind decrease, automatically. So is the way how green- houses work and this is also demonstrated [8]. The increase of the humidity, precipitation and of the water and air temperatures along with decreasing surface radiation, evaporation and winds is possible only with the increasing presence of the greenhouse effect.

The "closing” of the Earth's atmosphere is made either by increase of the percentage, thickness and darkening of clouds, which conditions change the convection, evaporation and radiation behaviors. Concentrations of water vapor and of other greenhouse gases also contribute for the modification of the normal path and intensity of the incoming and outgoing radiation. Transparent covers (glass, clouds, plastic, water vapor, gases, etc.), reflect and absorb and thus reduce the radiation entering the system (greenhouse) in comparison to that of a system that does not own a cover. A thicker and more opaque cover reduces the transmitted solar radiation because the absorption of solar radiation by the cover is higher. Furthermore, this cover also changes the wind and the convection conditions within the greenhouse.

The absorbed energy in a common sheet of glass is much greater than in a thin sheet of plastic, and because of this the radiation entering the system with glass is lower than for the greenhouse with plastic, but the greenhouse effect with glass cover becomes much stronger than using this plastic, because of its stronger absorption of the incoming and outgoing infrared radiation and due to less heat loss by conduction-convection at the cover, as may happen with cloud covers. The $\mathrm{H}_{2} \mathrm{O}$ concentration in the atmosphere is much higher than the corresponding $\mathrm{CO}_{2}$ concentration and the absorption of infrared radiation by the $\mathrm{H}_{2} \mathrm{O}$ is also much higher than that by the $\mathrm{CO}_{2}$. Water vapor absorbs strongly in several bands of the more energetic part of the solar radiation spectrum, while the $\mathrm{CO}_{2}$ absorbs in a few and small bands of the less energetic part of the solar spectrum (e.g., [25]). "When the humidity is high, the water vapor attenuates the global irradiance from its extraterrestrial value of $53 \%$ to about $38 \%$ at the Earth's surface due to absorp- tion in the infrared portions of the spectrum” [26].

The water vapor combines its greatest amount in the atmosphere with its physical characteristic of most absorber to be the main greenhouse gas. A gas must satisfy these two conditions to be considered a greenhouse gas. The gases $\mathrm{CH}_{4}$ and $\mathrm{N}_{2} \mathrm{O}$ do not show absorption bands for the solar radiation spectrum, which means that they are not greenhouse gases for these radiation ranges. Measurements of the radiation emitted by the Earth's surface at temperatures of about $50^{\circ} \mathrm{C}$ at noon over the Northern Africa [12] show that the $\mathrm{CH}_{4}$ presents an absorption band at about $7.7 \mu \mathrm{m}(7700 \mathrm{~nm})$ and the $\mathrm{CO}_{2}$ at about 15 $\mu \mathrm{m}$, while the water vapor is again the major absorber over this infrared spectrum. Other online data confirm that the carbon dioxide is the second greenhouse gas. The average natural water vapor content $(40,000 \mathrm{ppm})$ in the atmosphere by volume is about 100 times greater than the carbon dioxide content (370 ppm) and about 23,000 times greater than the methane content (1.7 ppm) [27].

A simple exercise gives an insight of the relative influences of each gas on the greenhouse warming. If the atmosphere was constituted only by water vapor, the maintenance of its temperature would be $100 \%$ due to this gas, keeping constant all the other conditions. If the atmosphere was constituted only by water vapor and carbon dioxide and assuming their influences on the temperature to be linear, a simple rule of three gives the influence of each gas on the building of any temperature, taking into account the amounts by volume. For example, for a total amount of 40,370 ppm and for a $20^{\circ} \mathrm{C}$, the influence of the water vapor would be $19.82^{\circ} \mathrm{C}$ while that of the carbonic gas would be $0.18^{\circ} \mathrm{C}$. If the carbon dioxide was more absorber than the water vapor this result would be modified, but this is not the case. The relative influences of the other gases are less than these ones. If the gases amounts increase, the total amount also must increase, thus, if the carbon dioxide increased to 500 ppm, the above relative influences would be respectively equal to $19.75^{\circ} \mathrm{C}$ and to $0.25^{\circ} \mathrm{C}$. And if the water vapor increased to $45,000 \mathrm{ppm}$ and the total atmospheric amount was $45,500 \mathrm{ppm}$, the relative influences would be equal to $19.78^{\circ} \mathrm{C}$ and to $0.22^{\circ} \mathrm{C}$, respectively, that is, we cannot consider an increase of one gas isolately and neglect the others and the new totals.

The atmosphere of common places (not deserts) does not reach or remain with zero humidity and the humidity of the planet has increased in the last decades. The released heats by evaporation and convection from the Earth's surface are also absorbed by the atmosphere and help to increase the corresponding warming, as it happens within any greenhouse. Additionally, the $\mathrm{CO}_{2}$ is a gas that does not condense (such as ozone, nitrous oxide, methane and chlorofluorocarbons), and it is absorbed by water or water vapor, and so, with more humidity in the 
air, higher is the precipitation and more gas is withdrawn from the atmosphere and brought back to the Earth's surface.

Measurements confirming the reduction of surface solar radiation in the USA and worldwide in the last decades showed that this radiation declined $19 \mathrm{~W} / \mathrm{m}^{2}$ or $10 \%$ in the United States from the 1960's to 1980's and 7 $\mathrm{W} / \mathrm{m}^{2}$ or $4 \%$ in other regions of the globe in three decades [2]. Liepert and other researchers (e.g., [3]) did not understand why reductions in surface solar radiation and evaporation have been simultaneous with observed increase in air temperature ([28] for the United States), cloudiness and precipitation in various parts of the world for the last decades. This paper (also supported mathematically by the referred demonstration), solves this correctly. As shown in Section 2, even with less radiation than for the corresponding open evaporator, the temperatures of greenhouses are much higher and the evaporation lower. In the case of the increased cloud cover, the radiation entering this Earth's greenhouse is reduced, but even so the inner temperatures increase and the evaporation decrease (like for other greenhouses). This greenhouse power for increasing the inner temperatures with comparatively less energy also shows us that the greenhouse is almost independent of the amount of solar energy, i.e., it warms with higher or lower solar energy received. It also shows us that the human influence on the greenhouse effect should be determined independently of such variations. Inversely, few clouds and/or less water vapor and/or other gases indicate that more direct sunlight reaches the Earth's surface just in this case of an open atmosphere, which warming variation can be due to solar radiation variations, including the ones caused by the Sun's cycles. Therefore, it is incorrect and impossible to attribute such warming to only one factor (natural or human-induced) without an accurate scientific analysis, as well as contrarily to the general belief the air temperature alone is not sufficient and cannot be used for the determination of a human influence on an atmospheric warming. The greenhouse effect (due to clouds and/or more water vapor) is what mainly matters and it is the concern in relation to the human influence on an atmospheric warming scenario and climatic changes.

Other satellite measurements [29] have also indicated that cloudy atmospheres absorb 50\% more radiation than predicted, which result harmonizes with the findings $[2,28]$ and can be a confirmation that the cloud amounts are increasing and getting thicker. This ARM-ARESE study also found no evidence for enhanced absorption of radiation in clear skies, and found strong evidence for enhanced radiation absorption in cloudy skies.

Satellite data [4] for February and August from 2002 to 2004 over California present a real indication of wind speed decrease associated with the cloud cover increase, showing that the average near-surface wind speed over land in August decreased from $4.2 \mathrm{~m} / \mathrm{s}$ (when the aerosol optical depth was low) to $3.5 \mathrm{~m} / \mathrm{s}$ (when aerosol readings were high). The trend for February was similar, with a decrease in wind speed from $7.5 \mathrm{~m} / \mathrm{s}$ for lower aerosol counts to $6.5 \mathrm{~m} / \mathrm{s}$ for higher aerosol counts. According to the authors, aerosol particles may also explain the reduction in the Asian seasonal monsoon and China's "disappearing winds". From 1974 to 1994 the wind speed in Southeast China dropped by $24 \%$ when aerosol optical depths increased from low to high levels. The authors also say that observed reduced wind speeds in Europe may also be due to the increase of cloud cover by aerosols. These results are also corroborated by [5] who compiled decades-long database of aerosols measurements over land and found that clear sky visibility has decreased over land globally from 1973 to 2007, indicative of an increase of particulates and darkness in the air over the world's continents during that time. The study [6] based on measurements on Earth's surface showing that the average and peak winds have decreased $10 \%$ or more per decade from 1973 to 2005 , especially in the Midwest and the East of the USA, is another confirmation of the demonstrations of the present paper on the working principles of greenhouses, and also that the Earth's greenhouse effect has increased in some places of the world, with the consequent reductions in evaporation, surface radiation and winds, while the clouds, the precipitation, the humidity and the water and air temperatures have increased. The cloud cover and greenhouse gases affect the radiation, but due to its denser and more solid condition the cloud cover closes the openings and thus converts the forced convection into the free convection, i.e., decrease the winds.

The work [7] completes and confirms the demonstrations of this paper on the correct working principles of greenhouses as well as on the real behavior of the Earth's greenhouse effect through their findings that 167 large lakes water temperatures worldwide increased since 1985. Using satellite data they found an average warming of $0.45^{\circ} \mathrm{C}$ per decade, with some lakes warming as much as $1.0^{\circ} \mathrm{C}$ per decade. The warming trends were global and mainly observed in Europe, North America, Siberia, Mongolia, China, and in the Southern Hemisphere. The satellites temperature trends also agreed with trends measured by nine buoys in the Great Lakes, the Earth's largest group of freshwater lakes in terms of total area and volume. The authors also report that the satellites measurements were in agreement with independent surface air temperature data from NASA's Goddard Institute.

The solution [3] believing that the evaporation has decreased in the last decades due to the reduction of the surface solar radiation resulting from energy losses by 
more clouds is erroneous at least by two reasons. First: the increase of the air and water temperatures in an open atmosphere is impossible with less energy and their statement violates the first law of thermodynamic, i.e., creates more energy from less energy. Second: if the Sun froze, all temperatures on Earth would go below zero, and thus would not rise, in contrast to how was simply supposed by the authors. The increase of the humidity, precipitation, water and air temperatures along with decreasing surface radiation, evaporation and winds is possible only with the increasing presence of the greenhouse effect! The greenhouse works like a second energy source storing energy and mass, and losing less heat and mass than a free water surface of an open atmosphere, while the free convection and the higher air temperature and humidity inside the greenhouse (caused by the addition of a cover) cause the evaporation and the wind to decrease, as well demonstrated in this paper.

However, since we have learned in basic studies that in the natural hydrological cycle the amount of precipitation is equal to the amount of evaporation a question arises: how is it possible that clouds and rain have increased with less evaporation? Let's analyze the hydrological cycle and put it in form of equation (this has never been done before). Hence, making the water mass balance for a selected system (control volume) at the Earth's surface we get:

Rate of water mass accumulation (at water, soil and vegetation bodies) = Rate of water mass in (precipitation) rate of water mass out (evaporation),

or

$$
\mathrm{dMas} / \mathrm{d} \theta=\mathrm{dMp} / \mathrm{d} \theta-\mathrm{dMev} / \mathrm{d} \theta
$$

where Mas = accumulated water mass at a selected system of the Earth's surface (kg), Mev = mass of water by evaporation $(\mathrm{kg}), \mathrm{Mp}=$ mass of water by precipitation (kg), and $\theta=$ time (h).

Therefore, in places where there was high precipitation, high humidity and low evaporation, there was an accumulation on the Earth's surface, or, the variation of water mass accumulation dMas was positive and the places became more humid; in places where there was higher evaporation than precipitation, such variation was negative and the places became drier. We can have different precipitation and evaporation rates in a same place in different periods and conditions, and different precipitation and evaporation rates in different places. It is normal and natural to have variations in the rate of accumulation, due to variations in rates of precipitation and evaporation, which rates depend on several factors and conditions.

The equation of the natural hydrological cycle is completed when we make the water mass balance for a system (control volume) of the atmosphere:

Rate of water mass accumulation (clouds + water va- por $)=$ Rate of water mass in (evaporation) - rate of water mass out (precipitation),

or

$$
\mathrm{dMaa} / \mathrm{d} \theta=\mathrm{dMev} / \mathrm{d} \theta-\mathrm{dMp} / \mathrm{d} \theta
$$

where Maa = accumulated water mass in a selected layer of the atmosphere (kg).

Equation (3) also tells us that what matters is the amount of water vapor in the atmosphere, or, in other words, the variation of the accumulated amount is independent whether the molecules are new or old, because their influences in producing the greenhouse effect is the same, as also verified in the experimental tests of the closed evaporator, where new water molecules constantly rise, absorb thermal radiation, transfer heat by convection and heat and mass by evaporation, and help the warming in the same way as old molecules do. When there is a rainfall this does not mean that the air remains with zero water vapor, on the contrary, the air humidity (mass) increases. The water vapor and its influence do not exist only in clouds. When eventually the amount of precipitation, say new (or old) molecules, equals the amount of evaporation, say old (or new) molecules, this does not mean that there is zero water vapor in the atmosphere, this only means that the variation of such mass is zero in that moment and place. In humid climates, at any time, there is always a certain amount of water vapor in the air, composed by new and old molecules, and both are submitted to the same processes of absorption, reflection, transmission and emission of radiation, as well as both exchange heat by convection and heat and mass by evaporation with different layers of the atmosphere and help to change the greenhouse effect. A humid atmosphere does not reach zero water vapor, likewise the evaporation is never zero (unless the extreme case of saturation with equal temperatures is reached, as shown [9]). Thus, with higher or lower cyclic velocities of water in the air, the humid air will always contain significant amounts of water mass that continuously suffer the referred influences. And since the planet's humidity has increased this means that the Earth's greenhouse effect has increased due to the addition of more cover that traps the heat and humidity below. When you wish to cook more rapidly and save energy you must put the cover onto the pot, because this attitude increases the cooking temperatures. A food inside a closed pot with water is cooked, not grilled, because the humidity remains and gives the characteristic food flavor and texture. When a meat or other food is grilled (i.e., at an open system), there is not additional water as well as the food water evaporates and the food becomes dried and gives the characteristic flavor and texture. The conventional hydrological cycle can be seen schematically in Figure 3. 
The human influence alters the velocity of the natural cycles and the atmospheric heat and mass balances, being the solution to the question raised before given by the explanation that the evaporation has not been the only source for the cloud formation and the main reasons are: a) because droplets of condensed water vapor aggregate on microscopic dust particles (the cloud droplet nuclei or cloud condensation nuclei) the emissions of lots of tons of solid particles every second all over the world intensify the cloud formation and precipitation. Hence, we can say that there is also the "dust or aerosols cycle"; b) tons of superheated gases (including water vapor) emitted by fossil fuel power plants, nuclear plants, industries, and other sources are released with extremely high temperatures and then the air dew point temperature is reached more often and more water vapor is condensed in less time and form more clouds and rain; c) the emissions from nuclear plants, industries, fossil fuel power plants, etc, contain tons of superheated water vapor and when they make contact with cooler layers of the atmosphere more condensed water and clouds are formed; this also corresponds to mass and latent heat addition, which also increases the humidity of the air, which is an additional cause for the evaporation decrease. These causes explain why the cloudiness, the precipitation and the humidity have increased in almost the entire world.

Some places eventually less humid may present higher precipitation than more humid ones if their atmospheres contain more solid particles and heat and mass emissions, because these factors increase the formation of clouds and rain faster than the natural cycle does. Measurements [30] confirm that "the more the aerosol present, the more the cloud droplets". Such higher precipitation may be also due to wind currents that transport humidity, heat and pollutants. We could say that vertical currents feed, while horizontal currents transport.

Therefore, the behavior, the amount of water, the regularity of waters, the distribution of rain and the velocity of the hydrological cycle no longer depend solely on the natural processes of evaporation and precipitation as they were conceived and taught, and thus there is a new hy-
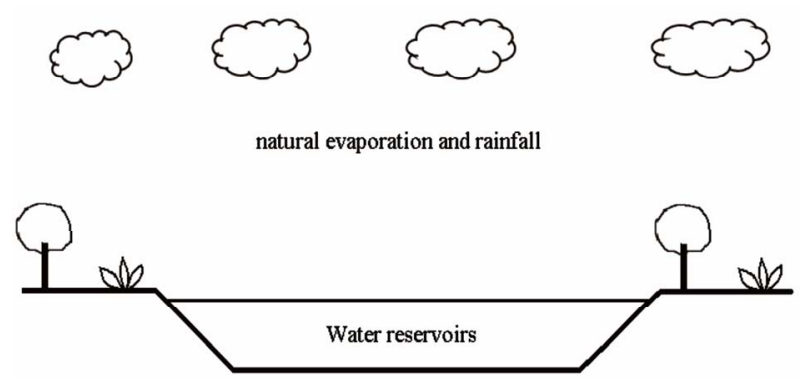

Figure 3. A simple representation of the conventional hydrological cycle. drological cycle and climatic changes which are consequences of certain human activities.

Thus, the new hydrological cycle has been discovered and registered by this author, which water mass balance for a system (control volume) at the Earth's surface includes the withdrawal of water from the surface and/or subterranean waters and released to the atmosphere by certain human activities:

Rate of water mass accumulation (at water, soil and vegetation bodies) = Rate of water mass in (precipitation) rate of water mass out (evaporation) - rate of water mass out (human activities),

or

$$
\mathrm{dMas} / \mathrm{d} \theta=\mathrm{dMp} / \mathrm{d} \theta-\mathrm{dMev} / \mathrm{d} \theta-\mathrm{dMh} / \mathrm{d} \theta
$$

where $\mathrm{Mh}=$ mass of water released to the atmosphere by human activities (kg).

The equation of the new hydrological cycle is completed when we make the mass balance for a system (control volume) of the atmosphere:

Rate of water mass accumulation (clouds + water vapor) $=$ Rate of water mass in (evaporation) + Rate of water mass in (total clouds and water vapor caused by human activities) - rate of water mass out (precipitation), or

$$
\mathrm{dMaa} / \mathrm{d} \theta=\mathrm{dMev} / \mathrm{d} \theta+\mathrm{dMh} / \mathrm{d} \theta-\mathrm{dMp} / \mathrm{d} \theta
$$

Since everything that rises must come back, the more intense and irregular the water mass and aerosols released to the atmosphere by human activities (Mh), the more intense and irregular will be such return to the Earth's surface after physical and chemical interactions in the atmosphere. The new hydrological cycle can be visualized schematically in Figure 4.

However, there should be a saturation limit for water vapor and particulates to generate more clouds and rain, since in a certain time in big and industrialized cities, over large agricultural dry fields, with intense burning of crops and forests, or at deforested areas, for example, the solid air particles in excess may not find sufficient water vapor to form more clouds and rain and thus accumulate in the atmosphere for a certain time creating a "solid" barrier or cover (Figure 5). This is apparently confirmed by Wang J. et al. [31] who found that shallow clouds tend to form over deforested areas of the Amazon while deep clouds are more prevalent above the dense and humid intact forest as well as the shallow clouds that developed over the forested areas normally became deep clouds. Rosenfeld et al. [32] also corroborate with this analysis through their findings that increasing aerosol concentrations below the optimum will boost rainfall, whereas increasing levels above the optimum will decrease rainfall. With intense burnings, the heat from smokes together with the air humidity may increase the formation 


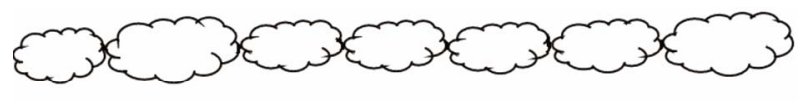

increased cloudiness and rainfall with decreased evaporation

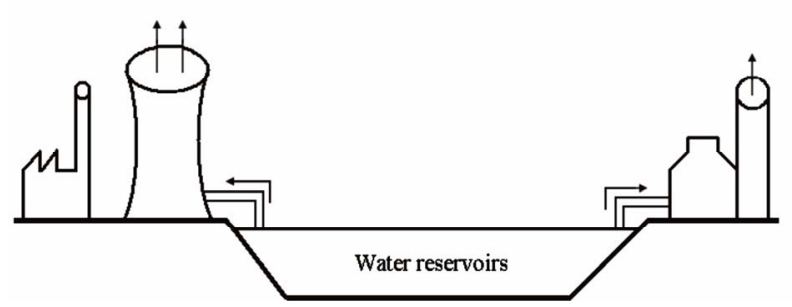

Figure 4. The new hydrological cycle reveals that certain human activities increase the formation of clouds and generate excess and irregular amounts and distributions of precipitation with consequent decreased evaporation.

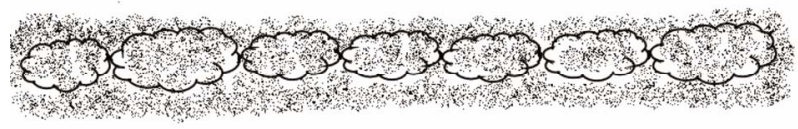

more solid barriers in skies or more "solid" cloud covers due to aerosols in excess with consequent less precipitation and more droughts

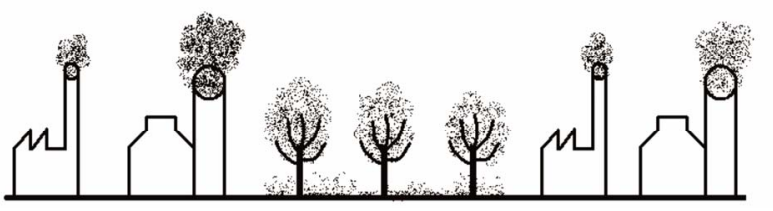

Figure 5. The new hydrological cycle also reveals that particles in excess in the air beyond the limit of water vapor due to certain human activities can generate the formation of solid barriers in skies and/or more "solid" cloud cover with consequent less precipitation and more droughts in uncertain periods and places.

of clouds and rain in a first moment, because the dew point temperature is reached more rapidly, however, when the limit of saturation approaches, more solid particles tend to remain in the atmosphere for a certain time.

In the case of polluted cities, such "solid" and contaminated barrier can cause the population to face respiratory and other health problems. It is interesting to note that the same principle (cloud condensation nuclei) that increases the formation of clouds when there is sufficient water content in the air may cause a "solid" barrier in the sky, with a consequent more opaque cover for the transmittance of light and radiation as well as for the outgoing infrared radiation. Such "solid" barrier also causes the cover to become more "closed" for the convection effects independently of the corresponding particles color. With such a "solid" and more "closed" atmosphere in these conditions, the rate of formation of clouds and rain is less (as also happens in the closed evaporator where the condensation of water vapor is less with an opaque cover), leading to an airless ambient and some drought conditions in uncertain periods and places.
In short, the new water cycle reveals and explains that certain human activities are more and more rapidly throwing water, heat and particulates in the air than the natural processes can do and which factors until certain limits of saturation increase the formation of clouds, precipitation and the greenhouse effect, with the consequent reduction of surface solar radiation, evaporation and winds. There is an increase of irregular amounts and irregular geographical and temporal distributions of precipitation and above the limits of saturation may cause droughts and other climatic changes due to several factors. However, many of the human-induced climatic causes and effects have technological and collaborative solutions just on Earth's surface.

\section{Conclusions}

The first principles that govern the operation of an open evaporator (free water surface) and of a closed evaporator (greenhouse effect) have been described in depth. Such physical principles are relevant for the better understanding of the very similar behaviors of the open (cloudless) and of the "closed" (totally cloudy) Earth's atmospheres. In these greenhouses, the water has been included, otherwise the corresponding heat and mass balances do not match. Thus, it is also incorrect to consider the radiation as the only energy transfer factor or forcing for an atmospheric warming. Most of the heat transfer from the Earth's surface to the atmosphere per square meter, per temperature difference and per total area is by evaporation, which increases substantially the greenhouse warming.

It is incorrect to state that the evaporation of open and closed evaporating systems increase based solely on the water or air temperatures, because there are many other factors that affect the evaporation at the same time in the opposite sense. For example, the ambient temperature increase plays a strong role in the evaporation decrease.

It is also a strong error to state that the evaporation must increase with the greenhouse effect increasing in comparison to an open evaporating system. Demonstrations (supported by mathematical calculations) based on fundamental laws that govern the evaporation have been performed and confirm these findings. It has been shown, among several other things, that when the cloud cover increases, the evaporation decreases. The evaporation is in the core of the greenhouse effect and of an atmospheric warming scenario, and accurate understandings and directions are thus enormously required.

Among several other things, it is very important to note that the interior of a greenhouse receives less energy than an open system and even so the temperatures of the closed one reach much higher values. This is how greenhouses behave and is another demonstration on why 
any considered amount of solar energy and water and air temperatures are not sufficient to guarantee higher or lower warming and evaporation when the greenhouse effect is involved.

Various researchers did not understand why reductions in surface solar radiation and pan evaporation have been happening simultaneously with observed increase in air temperature, cloudiness and precipitation in various parts of the world for the last decades. Some of them stated that more precipitation is not conciliatory with less evaporation and named their understandings as the "evaporation paradox", while others "found" "the cause" violating the laws of thermodynamics. However, more precipitation is perfectly and naturally conciliatory with less evaporation. Since in the last decades the cloudiness, the precipitation, the humidity and the water and air temperatures increased while the pan evaporation, the surface radiation and the winds decreased in some places of the world, this is the perfect proof that the Earth's greenhouse effect increased in such places and periods. The increase of the humidity, precipitation and water and air temperatures along with decreased surface radiation, evaporation and winds are possible only with the increasing presence of the greenhouse effect and of the cloud cover, as described in this paper. In the literature, temperatures increase have been related to only one factor (radiation), but there are many other parameters and causes that increase or decrease the temperatures.

It has also been generally said that in a greenhouse the convection is suppressed, but only the wind is suppressed, because when there are temperature differences the convection is not suppressed. Even tiny temperature differences keep small air movements, which keep the convection. That is, when an open system is covered, the convection is converted from forced to free convection, and this means that in an increasing Earth's greenhouse effect due to cloud cover increase the wind decreases, too. Various studies with measurements by satellites and on Earth present a real indication of a global wind speed decrease associated with the cloud cover increase, as expected and demonstrated by this author. Satellite data showing that more than 170 large lakes water temperatures worldwide increased since 1985 complete and confirm this paper description of the working principles of greenhouses as well as of the real and altered behavior of the Earth's greenhouse effect in some places and periods of the world.

Since the winds tend to disappear in a full greenhouse effect, how then tornadoes and hurricanes are explained? These are not linked to the greenhouse effect, but to strong pressure differences (where humans can also act), which can also be demonstrated physically and mathematically.

The hydrological cycle has been analyzed and put in form of equation (which analyses have never been done before) and the new hydrological cycle which is consequence of certain human activities (e.g., fossil fuel power plants, nuclear plants, industries, etc.) was discovered. The human influence alters the velocity and the behavior of the natural cycles as well as the atmospheric heat and mass balances, and the evaporation has not been the only source for the cloud and rain formation. Interesting to note that the same principle (cloud condensation nuclei), that increases the formation of clouds and rain may cause less precipitation and droughts. Several other relevant issues have been elucidated and correctly solved in the paper.

\section{REFERENCES}

[1] W. H. Brutsaert and M. B. Parlange, "Hydrological Cycle Explains the Evaporation Paradox,” Nature, Vol. 396, No. 30, 1998, p. 30. doi:10.1038/23845

[2] B. G. Liepert, “Observed Reductions of Surface Solar Radiation at Sites in the United States and Worldwide from 1961 to 1990," Geophysical Research Letters, Vol. 29, No. 10, 2002, pp. 1421-1433.

[3] M. L. Roderick and G. D. Farquhar, "The Cause of Decreased Pan Evaporation over the Past 50 Years," Science, Vol. 298, No. 5597, 2002, pp. 1410-1411.

[4] M. Z. Jacobson and V. J. Kaufman, "Wind Reduction by Aerosols Particles,” Geophysical Research Letters, Vol. 33, 2006, p. L24814.

[5] K. Wang, R. E. Dickinson and S. Liang, "Clear Sky Visibility Has Decreased over Land Globally from 1973 to 2007," Science, Vol. 13, 2009, pp. 1468-1470.

[6] S. C. Pryor, R. J. Barthelmie, D. T. Young, E. S. Takle, R. W. Arritt, D. Flory, W. J. Gutowski, A. Nunes and J. Roads, "Wind Speed Trends over the Contiguous United States,” Journal of Geophysical Research, Vol. 114, 2009, p. D14105.

[7] P. Schneider and S. J. Hook, "Space Observations of Inland Water Bodies Show Rapid Surface Warming since 1985,” Geophysical Research Letters, Vol. 37, 2010, p. L22405.

[8] E. Sartori, "Solar Still Versus Solar Evaporator: A Comparative Study between Their Thermal Behaviors," Solar Energy, Vol. 56, No. 2, 1996, pp. 199-206. doi:10.1016/0038-092X(95)00094-8

[9] E. Sartori, “A Critical Review on Equations Employed for the Calculation of the Evaporation Rate from Free Water Surfaces,” Solar Energy, Vol. 68, No. 1, 2000, pp. 77-89. doi:10.1016/S0038-092X(99)00054-7

[10] RGS-Royal Geographical Society, "Increasing Cloud Reflectivity,” 2011.

http://www.21stcenturychallenges.org/60-seconds/increas ing-cloud-reflectivity

[11] J. M. Haynes, G. L. Stephens, C. Mitrescu, S. D. Miller and T. S. Ecuyer, "Precipitation Estimation from CloudSat,” American Geophysical Union, Vol. 88, No. 52, 2007, 
pp. A1-A10.

[12] Harvard University, ACMG, SEAS, "The Greenhouse Effect,” Chapter 7, 2011.

http://acmg.seas.harvard.edu/people/faculty/djj/book/boo kchap7.html\#10575

[13] L. V. Alexander, X. Zhang, T. C. Peterson, J. Caesar, B. Gleason, T. A. Klein, M. Haylock, D. Collins, B. Trewin, F. Rahimzadeh, A. Tagipour, K. K. Rupa, J. Revadekar, G. Griffiths, L. Vincent, D. B. Stephenson, J. Burn, E. Aguilar, M. Brunet, M. Taylor, M. New, P. Zhai, M. Rusticucci and J. L. Vazquez-Aguirre, "Global Observed Changes in Daily Climate Extremes of Temperature and Precipitation," Journal of Geophysical Research, No. 111, 2006, p. DO5109.

[14] P. Y. Groisman, R. W. Knight, D. R. Easterling, T. R. Karl, G. C. Hegerl and V. N. Razuvaev, "Trends in Intense Precipitation in the Climate Record," Journal of Climate, Vol. 18, No. 9, 2005, pp. 1326-1350. doi:10.1175/JCLI3339.1

[15] IPCC, 2011. http://www.ipcc.ch

[16] E. Sartori, “A Mathematical Model for Predicting Heat and Mass Transfer from a Free Water Surface,” ISES Solar World Congress, Hamburg, No. 2, 1987, pp. 31603164.

[17] E. Sartori, "Prediction of the Heat and Mass Transfer from a Free Water Surface in the Turbulent Flow Case," ISES Solar World Congress, Kobe, No. 3, 1989, pp. 2343-2347.

[18] E. Sartori, "The Thermal Inertia and the Conduction Heat Loss Effects on the Solar Evaporator,” Renewable Energy Congress, Reading, 1990, pp. 1110-1114.

[19] E. Sartori, "Evaporation from a Free Water Surface with Salt Concentration,” ISES Solar World Congress, Denver, 1991, pp. 2347-2351.

[20] E. Sartori, “Letter to the Editor," Solar Energy, Vol. 73, No. 6, 2003, p. 481.

[21] E. Sartori, "Letter to the Editor," Solar Energy, Vol. 82, No. 10, 2008, pp. 956-958. doi:10.1016/j.solener.2008.02.004

[22] V. P. Singh and C. Y. Xu, "Evaluation and Generalization of 13 Mass-Transfer Equations for Determining Free Water Evaporation,” Hydrological Processes, Vol. 11, No. 3, 1997, pp. 311-323.

[23] E. Sartori, “Convection Coefficient Equations for Forced
Air Flow over Flat Surfaces,” Solar Energy, Vol. 80, No. 9, 2006, pp. 1063-1071. doi:10.1016/j.solener.2005.11.001

[24] M. L. Roderick and G. D. Farquhar, "Changes in Australian Pan Evaporation from 1970 to 2002,” International Journal of Climatology, Vol. 24, 2004, pp. 1077-1090.

[25] J. A. Duffie and W. A. Beckman, "Solar Engineering of Thermal Processes,” 3rd Edition, Wiley, Hudson, 2006.

[26] P. J. Lunde, “Solar Thermal Engineering,” Wiley, Hudson, 1980.

[27] ACS - American Chemical Society, "Chemistry in Context: Applying Chemistry to Society,” 6th Edition, McGrawHill, New York, 2009.

[28] J. E. Hansen, R. Ruedy, M. Sato, M. Imhoff, W. Lawrence, D. Easterling, T. Peterson and T. Karl, "A Closer Look at United States and Global Surface Temperature Change,” Journal of Geophysical Research, Vol. 106, No. D20, 2001, pp. 23947-23963.

[29] C. S. Zender, B. Bush, S. K. Pope, A. Bucholtz, W. D. Collins, J. T. Kiehl, F. P. Valero and J. Vitko, “Atmospheric Absorption during the Atmospheric Radiation Measurement (ARM) Enhanced Shortwave Experiment (ARESE)," Journal of Geophysical Research, Vol. 102, No. D25, 1997, pp. 29901-29915.

[30] BNL-Brookhaven National Laboratory, “Aerosols,” 2011. www.bnl.gov

[31] J. Wang, F. J. Chagnon, E. R. Williams, A. K. Betts, N. O. Renno, L. A. Machado, G. Bisht, R. Knox and R. L. Bras, "Impact of Deforestation in the Amazon Basin on Cloud Climatology," Proceedings of the National Academy of Sciences of the United Nations of America, Vol. 106, No. 10, 2009, pp. 3670-3674. doi:10.1073/pnas.0810156106

[32] D. Rosenfeld, U. Lohmann, G. B. Raga, C. D. O’Dowd, M. Kulmala, S. Fuzzi, A. Reissell and M. O. Andreae, "Flood or Drought: How Do Aerosols Affect Precipitation?” Science, Vol. 321, No. 5894, 2008, pp. 1309-1313. doi:10.1126/science.1160606

[33] S. L. Yu and W. H. Brutsaert, "Evaporation from Very Shallow Pans," Journal of Applied Meteorology, Vol. 6, No. 2, 1967, pp. 265-271.

[34] I. S. Bowen, "The Ratio of Heat Losses by Conduction and by Evaporation from Any Water Surface," Physical Review, Vol. 27, No. 6, 1926, pp. 779-787. 


\section{Appendix}

There are lots of equations for calculating the evaporation rate from free water surfaces and it is impossible to review all of them in a single paper or in an appendix. Sartori [9] reviewed 21 of them while [22] evaluated 13 of them. Singh-Xu made such evaluation based on generic data and using statistical analysis that focused almost only on errors and that produced generic results for uncertain water surfaces and uncertain periods and places of the planet.

Thus, in this appendix the 13 equations from [22] plus the Sartori equation are reviewed through direct comparisons with real experimental data, which comparisons produce objective results on the accuracy of each equation.

The paper [33] probably is the only one or the very rare one that presents almost all of the real data needed for the proper application of equations, such as the water temperature, the air temperature, the wind velocity, the relative humidity, periods of tests, pan sizes, pan colors, etc., and is thus very appropriate for direct comparisons of real data from pans working under different conditions. The evaporation does not have different names, because the only corresponding real physical phenomenon that happens from any wet surface, independently of water body sizes, for example, is only and simply the evaporation.

When a free water surface is exposed to the atmosphere it suffers influence from the wind velocity, the air temperature, the relative humidity, the solar radiation, and also from the atmospheric pressure and the physical structure. The water temperature is the final result of all interactions of the water layer with the environment after all heat and mass gains and losses.

The 14 equations are:

Dalton: $E=15\left(e_{s}-e_{a}\right)[\mathrm{in} / \mathrm{mo}]$

Fitzgerald: $\quad E=(0.4+0.199 \mathrm{u})\left(e_{s}-e_{a}\right)[\mathrm{in} / \mathrm{mo}]$ (A2)

Meyer: $E=11(1+0.1 \mathrm{u})\left(e_{s}-e_{a}\right)[\mathrm{in} / \mathrm{mo}]$

Horton: $E=0.4(2-\exp (-2 \mathrm{u}))\left(e_{s}-e_{a}\right)[\mathrm{in} / \mathrm{mo}](\mathrm{A} 4)$

Rowher : $E=0.77(1.465-0.0186 \mathrm{~Pb})$

$$
\cdot(0.44+0.118 \mathrm{u})\left(e_{s}-e_{a}\right)[\mathrm{in} / \mathrm{day}]
$$

Penman: $E=0.35\left(1-0.24 \mathrm{u}_{2}\right)\left(e_{s}-e_{a}\right)[\mathrm{in} / \mathrm{day}]$

Harbeck1: $E=0.0578 \mathrm{u}_{8}\left(e_{s}-e_{a}\right)[\mathrm{in} /$ day $]$

Kuzmin: $\quad E=6.0\left(1+0.21 \mathrm{u}_{8}\right)\left(e_{s}-e_{a}\right)[\mathrm{in} / \mathrm{mo}]$

Harbeck2: $E=0.001813 \mathrm{u}\left(e_{s}-e_{a}\right)$

$$
\cdot\left(1-0.03\left(T_{a}-t_{w}\right)\right)[\mathrm{in} / \mathrm{day}]
$$

Konstantinov : $E=\left(0.024\left(\left(t_{W}-t_{a}\right) / \mathrm{u}_{1}\right)\right)$

$$
+\left(0.166 \mathrm{u}_{1}\right)\left(e_{s}-e_{a}\right)
$$

$$
\text { Romanenko: } \begin{aligned}
E= & 0.0018\left(\mathrm{~T}_{\mathrm{a}}+25\right)^{2} \\
& \cdot(100-\mathrm{rh})[\mathrm{cm} / \mathrm{mo}]
\end{aligned}
$$

Sverdrup :

$$
\begin{aligned}
& E=\left(0.623 \rho \mathrm{K}^{2} \mathrm{u}_{8}\left(e_{s}-e_{a}\right) / \mathrm{Pb} \cdot\left([\ln 800 / 200]^{2}\right)\right) \\
& {[\mathrm{cm} / \mathrm{s}]}
\end{aligned}
$$

Thornthwaite-Holzman :

$$
\begin{aligned}
E= & \left(0.623 \rho \mathrm{K}^{2}\left(\mathrm{u}_{8}-\mathrm{u}_{2}\right)\left(e_{s}-e_{a}\right)\right) / \mathrm{Pb} \\
& \cdot\left([\ln (800 / 200)]^{2}\right)[\mathrm{cm} / \mathrm{s}]
\end{aligned}
$$

Sartori :

$$
E=0.0041 V^{0.8} L^{-0.2}\left(\mathrm{P}_{\mathrm{w}}-\phi \mathrm{P}_{\mathrm{a}}\right) / P\left[\mathrm{~kg} / \mathrm{m}^{2} \mathrm{~s}\right]
$$

Since [33] did not measure the wind velocity $\mathrm{u}_{8}$, then it has been estimated from the data [33] through the formula

$$
\mathrm{u}_{8}=\mathrm{u}_{3}\left(\mathrm{~h}_{8} / \mathrm{h}_{3}\right)^{0.15}
$$

In these equations, $\mathrm{E}=$ evaporation rate; $e_{a}, e_{s}=$ water vapor partial pressures at the air $\left(\mathrm{ta}_{\mathrm{a}}\right)$ and water $\left(\mathrm{t}_{\mathrm{w}}\right)$ temperatures, respectively (inHg); $\mathrm{h}_{3}, \mathrm{~h}_{8}=$ heights at $3 \mathrm{~m}$ and $8 \mathrm{~m}(\mathrm{~m}) ; \mathrm{K}=$ von Kármán constant = 0.41; L = surface length of water in the wind direction (m); $\mathrm{P}=$ atmospheric pressure (Pascal); $\mathrm{P}_{\mathrm{b}}=$ atmospheric pressure (in $\mathrm{Hg}$ ); $\mathrm{P}_{\mathrm{a}}, \mathrm{P}_{\mathrm{w}}=$ water vapor partial pressures at the air and water temperatures (Pascal); rh = relative humidity (percent); $\mathrm{t}_{\mathrm{W}}=$ water temperature $\left({ }^{\circ} \mathrm{C}\right) ; \mathrm{T}_{\mathrm{a}}={ }^{\circ} \mathrm{C}+1.9^{\circ} \mathrm{C}$ (for eq. A9 only); $u, u_{1}, u_{2}, u_{3}, u_{8}=$ wind velocity at surface level and at heights $1 \mathrm{~m}, 2 \mathrm{~m}, 3 \mathrm{~m}$ and $8 \mathrm{~m}$ above surface (miles/h); $V=$ wind velocity $(\mathrm{m} / \mathrm{s}) ; \rho=$ density of air (l $\left.\mathrm{b} / \mathrm{ft}^{3}\right) ; \phi=$ relative humidity (fraction).

$\mathrm{Yu}$ and Brutsaert tested 3 pan sizes painted black, white, gray and green. The sizes $4 \mathrm{ft}(1.2 \mathrm{~m})$ and $8 \mathrm{ft}(2.4$ $\mathrm{m})$ and the colors black and white are sufficient for the present comparisons and validation. Figures A1-A4 show the results of these comparisons. All equations were calculated as they are with their own units, being the final results converted to $\mathrm{mm} / \mathrm{h}$ and then included in the graphs.

The results from the Romanenko and Sverdrup equations could not be included in the graphs because their values fall off the scales. For each one of the four pans $(4 \mathrm{~B}, 4 \mathrm{~W}, 8 \mathrm{~B}, 8 \mathrm{~W})$ the minimum and maximum values from the Romanenko equation are always 6.98 and 78.77 $\mathrm{mm} / \mathrm{h}$, while from the Sverdrup equation these values are: $4 \mathrm{~B}=-6.28$ and $17.16 \mathrm{~mm} / \mathrm{h} ; 4 \mathrm{~W}=-11.41$ and 3.26 $\mathrm{mm} / \mathrm{h} ; 8 \mathrm{~B}=-5.33$ and $21.27 \mathrm{~mm} / \mathrm{h} ; 8 \mathrm{~W}=-11.52$ and $3.6 \mathrm{~mm} / \mathrm{h}$, respectively.

It is not the scope of this appendix to make a full analysis of the equations, but the equations that use the 
$\left(e_{s}-e_{a}\right)$ difference consider that $\mathrm{t}_{\mathrm{W}}$ is always higher than $\mathrm{t}_{\mathrm{a}}$ (because $e_{\mathrm{s}}$ and $e_{a}$ depend directly on $\mathrm{t}_{\mathrm{w}}$ and $\mathrm{t}_{\mathrm{a}}$, respectively), which is not always true, and then such difference often gives negative values that generate an invalid condition for the evaporation. These negative values do not correspond to the condensation of the water vapor on the water surface ("negative evaporation"), as calculated correctly and experimentally verified [16].

The Romanenko equation owns parameters only for the air and not for the water, therefore, it has nothing to do with water and evaporation and for it doesn't matter whether there is an ocean or a desert, because it does not depend on the water conditions and does not produce results for water surfaces. This is also verified in present calculations. Only an analysis not based on real and objective data could rank such equation as one of the most important.

As can be seen in the graphs, only one equation produced the correct and close agreement with experimental tests and best reproduces with high accuracy the behavior of the nature, independently of sizes, colors, different ambient conditions and amounts of water. It is also interesting to note in Figures A1-A4 that the Sartori equation

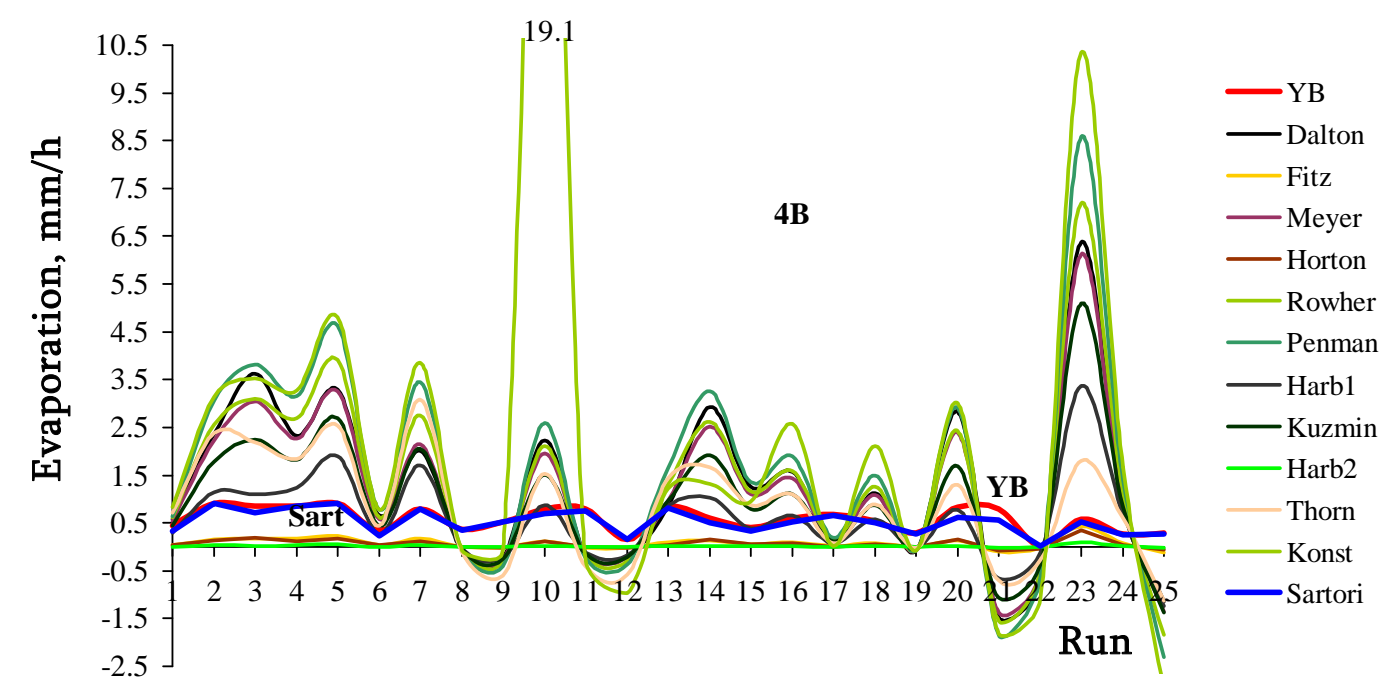

Figure A1. Comparison of equations results with the experimental data [33] for a $1.2 \mathrm{~m}$ square pan painted black (4B).

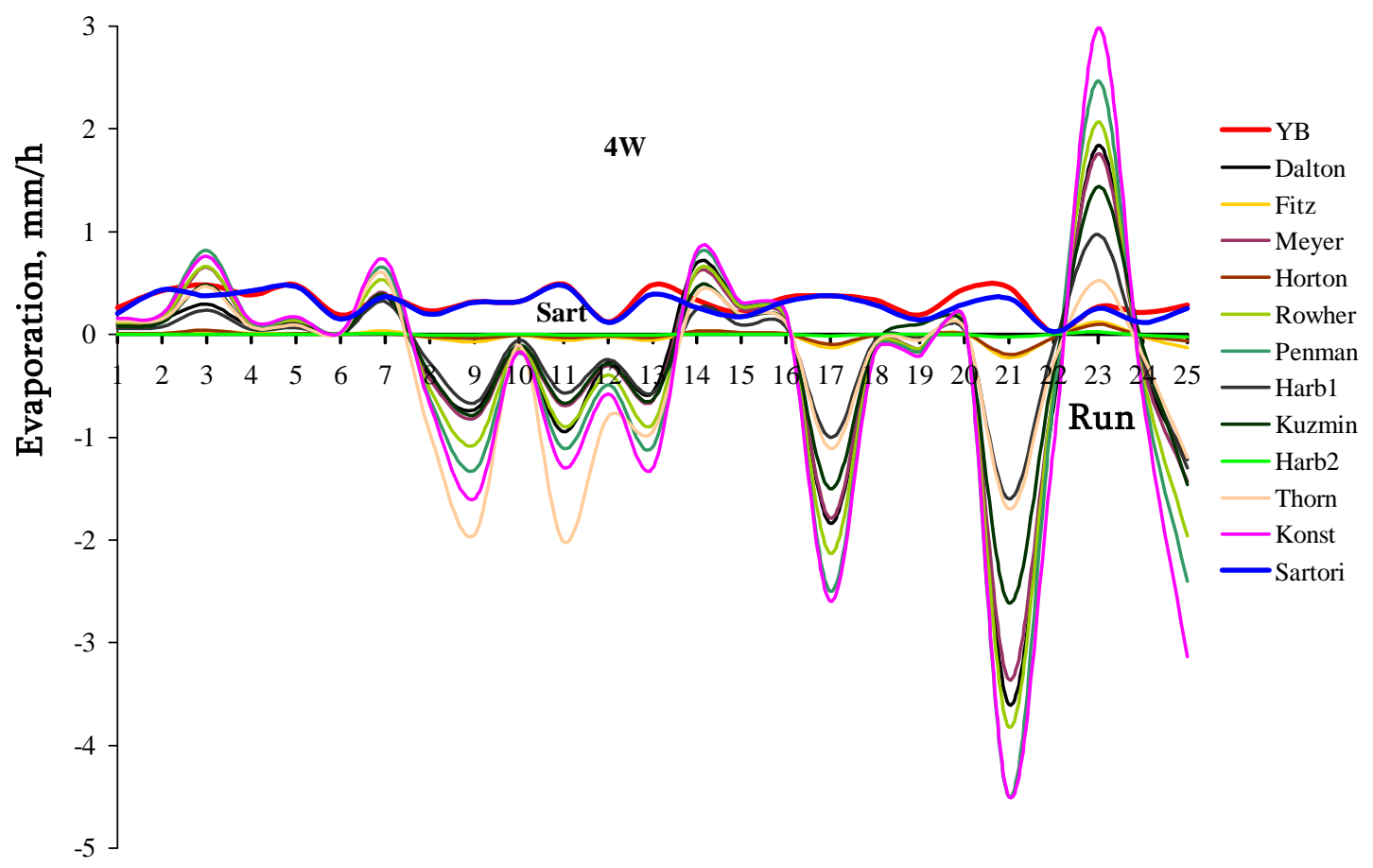

Figure A2. Comparison of equations results with the experimental data [33] for a $1.2 \mathrm{~m}$ square pan painted white (4W). 


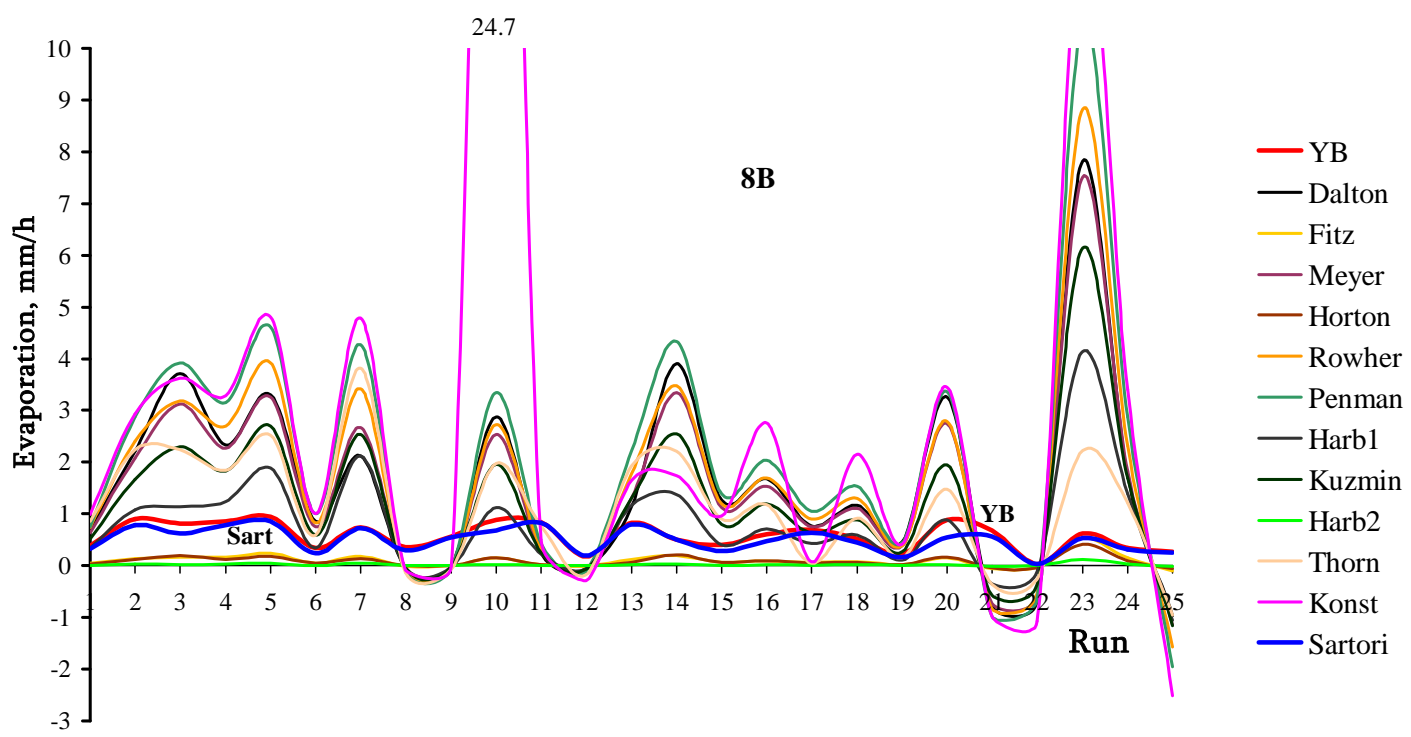

Figure A3. Comparison of equations results with the experimental data [33] for a $2.4 \mathrm{~m}$ square pan painted black (8B).

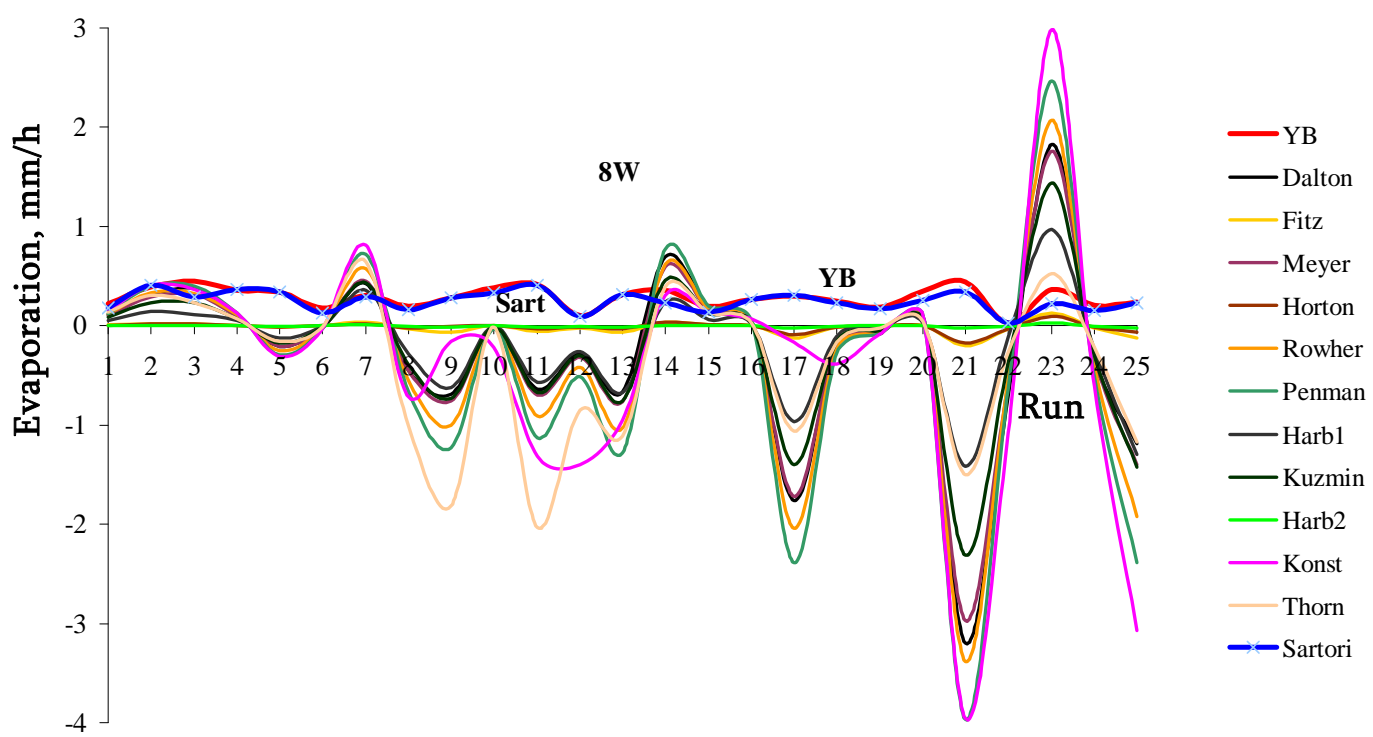

Figure A4. Comparison of equations results with the experimental data [33] for a $2.4 \mathrm{~m}$ square pan painted white (8W).

produced almost the same excellent accuracy for all of the situations, independently of sizes and of several other conditions. For example, the difference between $\mathrm{L}=$ $(1.2)^{-0.2}$ and $\mathrm{L}=(2.4)^{-0.2}$ is $13 \%$ and if the $\mathrm{L}$ was not taken into account such error would be introduced in the results.

Furthermore, through the Sartori equation the evaporation can be calculated even for the condition when $t_{a}>$ $\mathrm{t}_{\mathrm{w}}$, as well as the inedited condensation (dew) of the water vapor of the air onto the water surface can be obtained when $t_{d}>t_{w}$. In this equation the laws that govern the evaporation are taken into account and no other equation owns all these correct requirements and fundamental features.
The Sartori equation is the result of the combination among the Bowen equation [34], the Bowen-Sartori equation and the boundary layer theory $[8,9,16,17]$. Bowen's equation was derived theoretically through an analysis on a differential control volume of a fluid element flowing over a water surface. The boundary layer theory is the basis of the science on convection heat and mass transfer, is based on first principles verified experimentally and is mandatory for any fluid flow over wet and dry surfaces. Also, as demonstrated $[9,23]$, the evaporation and the convection coefficient depend on $\mathrm{V}^{0.8}$ and $\mathrm{L}^{-0.2}$ (for turbulent flow) and not linearly on $\mathrm{V}$ and $L$, as used in the 13 and in the lots of other equivalent equations obtained empirically. 